\title{
Upaya Penataan PKL Diperkotaan: Studi Kasus di Jalan Kaliurang
}

\author{
Suparwoko.
}

On one hand the existence street vendors ( $P K L$ ) have a positive impact on its economic contribution including employment and economic income. of lower people in urban areas. On the other hand, the existence of the streets vendors in urban areas has been blamed because they are making some problems of urban traffic jams and the beautification of cities. As a matter of the fact, they are needed by many people living in urban areas because they can provide cheap goods and services. The paper is to examine the location and place where street vendors are trading during the day and night. The growth of street vendors along the Jalan Kaliurang is due to the potential public facility established along the jalan Kaliurang such as campus, housing, and commercial facilities. The research suggests it is possible to integrate the street vendors as informal sector exist together with formal sector in certain areas. The other alternative of street vendor arrangement is that they can possibly working together with any commercial facility along jalan Kaliurang by using its parking area during the night where some of the commercial facilities do not operate in the night:

Kata kunci: $P K L$, jalan Kaliurang, fasilitas publik dan komersial

$\mathrm{K}$

ondisi perkotaan di Indonesia, seperti juga perkotaan di dunia ketiga, banyak dijumpai pedagang kaki lima (PKL) sebagai akibat tidak mampunya pemerintah mengatasi masalah migrasi, pengangguran dan kemiskinan. Masalah migrasi ke kota tejjadi karena kondisi perdesaaan, terutama pertanian, belum bisa menopang perekonomian masyarakat desa (Alimi, 2004). Sehingga pengelola kota masih banyak memikirkan sektor formal yang lebih mudah dikontrol. Padahal sektor infomal memiliki kontribusi yang nyata bagi pengatasan masalah pengangguran dan masalah perekonomian kawasan perkotaan (Cross, 2000)
Di Asia, sektor ekonomi informal mampu tumbuh lebih cepat dibanding sektor ekonomi formal. Sebagai bagian sektor yang mandiri, PKL telah mampu menciptakan jenis matapencaharian bagi banyak tenaga kerja yang tidakmendapat kesempatan keja formal atau mereka yang telah kehilangan pekerjaan akibat krisis ekonomi Asia 1997-1998, khusus nya di Thailand, Indonesia, dan Pilipina. Hasil riset ILO (International Labour Organisation) bahwa di tiga negara Asia menunjukkan bahwa sektor ekonomi informal mampu memberikan kontribusi terhadap tenaga kejja sebesar $96 \%$ di India, $93 \%$ di Indonesia and $73 \%$ di Pilipina (Streetnet, 2005).

Para PKL memiliki kecenderungan menempati ruang atau fasilitas publik di kawasan perkotaan dan mereka cenderung pula inenempati lokasi usaha tanpa 
melakukan ijin terlebih dahulu seperti di lapangan terbuka, menempel pada pasar atau bangunan, pada tanah yang kurang terkontrol dan tidak dikembangkan, di badan jalan dan trotoar (Reddy, Naidu, \& Mohanty, 2002). Kondisi semacam ini dikarenakan para PKL selalu ingin mendekati keramaian untuk memperoleh para pembeli, dimana para PKL beraglomerasi di simpul-simbul jalur jalan, trotoar dan tempat-tempat yang banyak dikunjungi banyak orang seperti pasar, terminal dan area komersial lainnya. Jenis dagangan dipengaruhi oleh aktivitas yang ada disekitar lokasi PKL berjualan (McGee \& Yeung, 1977).

Sarana prasarana $P K L$ pada umumnya sederhana, mudah dipasang dan dibawa atau dipindahkan. Pola aktivitas PKL menyesuaikan irama dari kehidupan masyakarat sehari-hari dengan cara pelayanan menertap atau berpindah-pindah yang dipengaruhi waktu dan kegiatan di lokasiberdagang PKL (McGee \& Yeung, 1977). Dari aspek tata ruang, PKL tumbuh dan berkembang disekitar kegiatan fungsional perkotaan dengan menempati ruang publik yang kurang mendapatkan perhatian dalam penataan kota dimana para PKL secara umum juga melakukan kegiatan usaha diluar kerangka hukum atau peraturan dan seringkali menjadi obyek pemalakan. Dalam masyarakat $P K L$ sistem diluar hukum formal yang mengatur lokasi berdagang ditepi jalan untuk keamanan dan tanpa aturan tertulis para PKL mencoba memperoleh pengakuan tambahan atau pertindungan untuk hak milik khusus dari pemerintah dengan membayar "pungutan". Pungutan semacam ini tidak memberi hak pada PKL atas lokasi dalam batas-batas peraturan pemerintah (Natalivan \& Dwiananto, 2005).

\section{Jalan Kaliurang dan PKL}

Jalan kaliurang merupakan barupakan bagian dari kawasan tumbuh cepat di Kabupaten Sleman. Kawasan tumbuh cepat merupakan kawasan yang telah berkembang atau potensial untuk dikembangkan, yang memiliki keunggulan geografis dan produk unggulan yang dapat menggerakkan pertumbuhan ekonomi wilayah sekitarnya (Departemen Kimpraswil, 2000). Kawasan tumbuh cepat disekitar jalan primer di Kabupaten Sleman adalah kawasan ditepi jalan Yogyakarta - Tempel, Yogyakarta Kaliurang, dan Yogyakarta - Prambanan (Pemerintah Kabupaten Sleman, 2003). Adapun potensi yang menonjol disekitar Jalan Kaliurang adalah Kampus UGM di Jl. Kaliuarang $\mathrm{Km} 4$ dan adanya kampus UII dan Akper Betesda di Jl. Kaliurang Km 14. Karena potensi UGM dan UII maka sepanjang jalan Kaliurang tumbuh berbagai fasilitas umum dan komersial seperti perumahan, pertokoan, perkantoran, fasilitas perbelanjaan.

Perkembangan kawasan tumbuh cepat juga dipengaruhi adanya pertumbuhan aglomerasi perkotaan Yogyakarta dan

Tabel 1. Potensi PKL, Konsumen dan Wilayah Keramaian.

\begin{tabular}{|c|c|c|c|c|c|}
\hline Kecamatan & $\begin{array}{c}\text { Perguruan } \\
\text { Tinggi }\end{array}$ & \# Mahasiswa & $\begin{array}{c}\text { Warung/ } \\
\text { Toko }\end{array}$ & PKL & Keterangan \\
\hline Mlati & 9 & Tidak ada data & 1.170 & 158 & \multirow{4}{*}{$\begin{array}{l}\text { Jalan Kaliurang berada di } \\
\text { wilayah Kecamatan } \\
\text { Depok, Ngaglik, dan } \\
\text { Ngemplak }\end{array}$} \\
\hline Gamping & 5 & Tidak ada data & & 92 & \\
\hline Depok & 17 & 123.441 & 2.567 & 312 & \\
\hline Ngaglik & 5 & 1.736 & 1.015 & 141 & \\
\hline
\end{tabular}

Sumber: (BPS Kabupaten Sleman, 2003a, 2003b, 2003c, 2003d) (Dinas Perhubungan DIY, 2004), (Bagian Pengembangan Perekonomian - Sekretariat Daerah Kabupaten Sleman, 2003) 
adanya potensi wilayah Sleman yang banyak memiliki perguruan tinggi dan mahasiswa dibanding dengan wilayah lain di DIY (lihat Tabel 1). Hampir $90 \%$ jumlah mahasiswa di DIY kuliah di perguruan tinggi yang berlokasi di Kabupaten Sleman. Hingga tahun 2003 jumlah PKL di Kabupaten Sleman mencapai 3000 , diman masing-masing PKL memperkerjakan 2-5 orang (Prabowo, 2005). Sedangkan jumlah PKL menurut hasil penelitiah Bagian Perekonomian Kabupaten Sleman (2003) tahun 2003adalah234. Dalam hal ini jenis usaha PKL dikelompokkan menjadi 3 jenis yaitu:

1. Jenis pengolahan makanan, seperti penjula pecel lele, ayam bakar, rawon,
2. Jenis Perdagangan, seperti penjual buah, roko, majalah, helm, rak buku, :dsb.

3. Jenis Jasa, seperti penjual tukang kunci, stempel, tambal ban, afdruk foto, stel porek, dsb.

Sedangkan jumlah dan jenis PKL di Jalan Kaliurang yang terbanyak adalah jenis pengolahan makanan (lihat Tabel 2) yang pada úmumnya melayani mahasiswa dan masyarakat umum.

Sebagian besar dari PKL adalah mengelompok, dan sebagian pengelompokan tersebut belum tentu mereka memiliki organisasi ataú paguyuban PKL. Namun dari para PKL di Sleman telah mendirikan

Tabel 2. Jumlah PKL di Jalan Kaliurang berdasar jenisnya, 2003

\begin{tabular}{|l|l|r|r|r|r|r|}
\hline No & Lokasi Jalan & Pengolahan & Perdagangan & Jasa & Jumlah & (\%) \\
\hline A & Kecamatan Depok & & & & & \\
\hline 2 & Jl. Kaliurang & 58 & 8 & 2 & 68 & 9 \\
\hline B & Kecamatan M lati & & & & & - \\
\hline 7 & Jl. Kaliurang & 35 & 9 & 8 & 52 & 2 \\
\hline C & Kecamatan Ngaglik & & & & & \\
\hline 1 & Jl. Kaliurang & 81 & 25 & 8 & 114 & 15 \\
\hline & Total & 174 & 42 & 18 & 234 & 26 \\
\hline
\end{tabular}

Sumber: (Bagian Pengembangan Perekonomian - Sekretariat Daerah Kabupaten Sleman, 2003)

Tabel 3. Tempat Usaha PKL di Kabupaten Sleman.

\begin{tabular}{|c|l|r|r|}
\hline No & \multicolumn{1}{|c|}{ Letak usaha } & Jumlah & $(\%)$ \\
\hline 1 & Pinggir jalan & 512 & 65 \\
\hline 2 & Trotoar & 182 & 23 \\
\hline 3 & Depan toko/warung & 69 & 9 \\
\hline 4 & Tidak diisi & 26 & 3 \\
\hline & Jumlah & 789 & 100 \\
\hline
\end{tabular}

Sumber: (Bagian Pengembangan Perekonomian - Sekretariat Daerah Kabupaten Sleman, 2003) Catatan:

- PKL pinggir jalan berarti PKL tempat usaha PKL berada bahu jalan

- PKL trotoar berarti tempat usaha PKL diatas trotoar

- Depan toko/warung berarti tempat usaha PKL berada di halaman toko, bengkel, rumah, dsb.

sop, soto, angkringan, nasi goreng, bakmi, sate, gudeg, dsb.) organisasi dengan nama PPKLS yang berdiri pada tanggal 2 Mei 2005 dengan keanggotaan sekitar 5 hingga 6 paguyuban 
dengan masing-masing paguyuban memiliki jumlah PKL antara 19 hingga 60 anggota (PPKLS, 2005).
1. Jarak antar letak PKL di trotoar pada siang hari tidak begitu masalah namun penggunaan seluruh lebar trotoar menjadi masalah bagi pejalan kaki.

Tabel 4. Jumlah dan Tanggapan Pejalan Kaki Pengguna Trotoar

\begin{tabular}{|l|c|c|c|}
\hline \multicolumn{1}{|c|}{ Lokasi } & Jam & Jumlah & \multicolumn{1}{c|}{ Tanggapan pejalan kaki terhadap Posisi PKL di trotoar } \\
\hline $\begin{array}{l}\text { Sisi Barat Jl. } \\
\text { Kaliurang Km }\end{array}$ & $12.00-13.00$ & 42. & $\begin{array}{l}\text { - Menurut saya PKL di trotoar ini tidak terlalu mengganggu pejalan } \\
\text { kaki karena jarak mereka yang berjauhan satu sama lainnya, jadi } \\
\text { tidak terlalu berpengaruh. Cuma kalau bisa ya jangan memakan } \\
\text { semua (lebar) trotoar, sisakan sedikitlah buat tempat lalu lalang". } \\
\text { - Menurut saya posisi PKL di trotoar ini sangat méngganggu apalagi } \\
\text { saat siang begini. Karena banyak lokasi yang rimbun/ teduh dipakai } \\
\text { - mereka untuk berdagang, sehingga jika ingin menunggu angkutan } \\
\text { kita di paksa ber panas-panasan." }\end{array}$ \\
\hline $\begin{array}{l}\text { Sisi Barat Jl. } \\
\text { Kaliurang Km } \\
\text { 4 UGM }\end{array}$ & $18.00-19.00$ & 35 & $\begin{array}{l}\text { - Sangat mengganggu dan membahayakan nyawa pejalan kaki. Lahan } \\
\text { parkir mereka yang mengambil badan jalan juga membuat pejalan } \\
\text { kaki harus mengambil agak ketengah jalan untuk lalu lalang. Di } \\
\text { tambah kondisi lalulintas malam yang semerawut membuat kita } \\
\text { yang.jalan ini mesti extra hati hati agar tidak di serempet motor }\end{array}$ \\
\hline
\end{tabular}

Sumber: data primer, 4 September 2005

Lahan publik yang diminati PKL adalah pinggir jalan dan trotoar (lihat Tabel 3 ) yang pada umum nya merupakan lahan milik pemerintah.

Sedangkan pendapat sejumlah pengguna trotoar ada yang setuju dan ada yang bisa memaklumi para PKL melakukan usaha di trotoar (lihat Tabel 4).
2. Letak PKL berada di tempat yang teduh mengganggu pejalan kaki untuk menunggu kendaraan umum

3. Letak PKL di trotoar pada malam hari sangat mengganggu karena mereka berada di hampir seluruh ruang trotoar dimana parkir pelanggan menggunakan sebagian ruang badan jalan (lihat

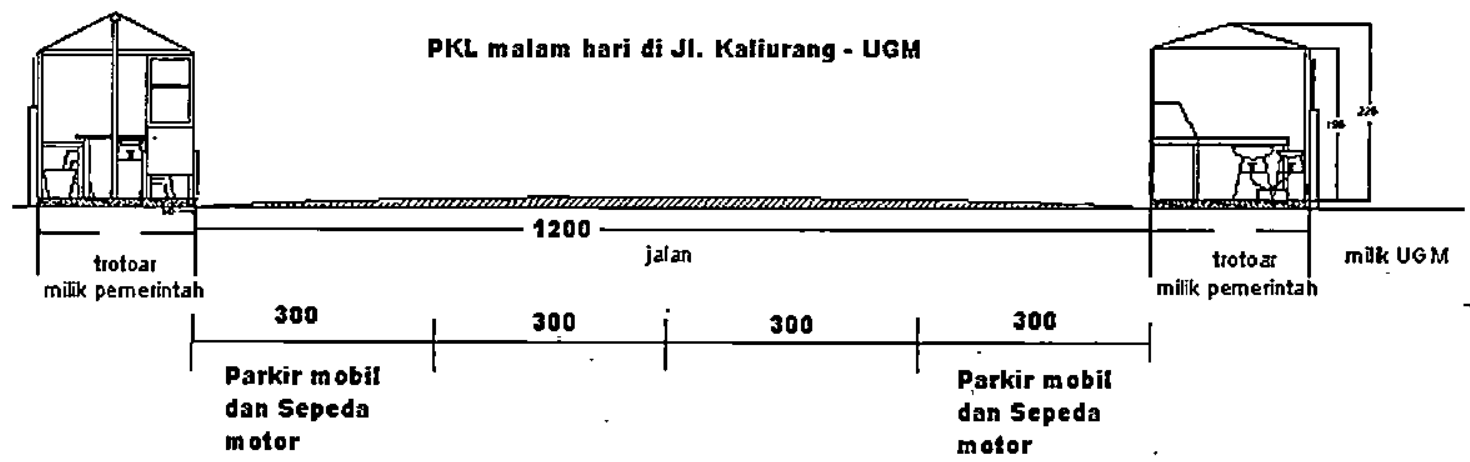

Gambar 1. PKL Malam Hari Jl. Kaliurang - UGM

Ditinjau dari lokasi PKL yang menggunakan trotoar maka yang menjadi masalah adalah:
Gambar 1 dan Lampiran 1) sehingga para pejalan kaki harus ekstra hati-hati berjalan di badan jalan. 
Keberadaan PKL sering dijadikan ukuran ketidakteraturan kota, yaitu kumuh dan kemacetan lalau lintas (Witjaksono, 2005). Sehingga aspek arsitektur PKL perlu diukur dari keterpaduan penampilan fungsi, bentuk, struktur, dan ekonomi. Menurut Badudu dan Zain (2001), kumuh berarti kotor dan tidak teratur.

1. Dari aspek fungsi dan ekonomi, Wirosardjono (1985) mengatakan bahwa pola kegiatan PKL tidak teratur dalam arti waktu, permodalan atau penerimaan.

2. Dari aspek bentuk dan struktur, McGee (1977) mengatakan bahwa bentuk dan struktur sarana prasarana PKL umumnya sederhana dan menyesuaikan jenis dagangannya.

Dari aspek penampilan PKL (bentuk dan struktur) tampak bahwa sebagian dari prasarana atau bangunan PKL adalah kotor serta letak mereka yang tidak teratur atau tidak pada tempatnya. Ukuran kumuh yang berkaitan dengan perletakkan PKL bisa diukur dengan perletakan mereka yang tidak teratur atau tidak semestinya yaitu berada di tempat publik seperti trotoar atau pinggir jalan.

Menurut Undang-undang RI No. 38/ 2004, jalan adalah prasarana transportasi darat yang meliputi segala bagian jalan, termasuk bangunan pelengkap dan perlengkapannya diperuntukkan bagi lalu lintas (Deputi Sekretaris Kabinet Bidang Hukum Perundang-undangan, 2004). Pasal 11 Undang-undang RI No. 38/2004 menjelaskan bahwa:

1. bagian-bagian jalan meliputi daerah manfaat jalan, daerah milik jalan, dan ruang pengawasan jalan.

2. Daerah manfaat jalan (Damaja) meliputi badan jalan, saluran tepi jalan, dan ambang pengamannya.
3. Daerah milik jalan (Damija) meliputi ruang manfaat jalan dan sejalur tanah tertentu diluar ruang manfaat jalan

4. Daerah pengawasan jalan (Dawasja) merupakan ruang tertentú diluar daerah milik jalan yang ada dibawah pengawasan penyelenggaraan jalan

Penempatan PKL di trotoar atau di pinggir jalan dinilai tidak teratu karena:

1. Fungsi trotoar berdasar aturan adalah sebagai jalur pejalan kaki

2. Fungsi jalan berdasar aturan adalah sebagai jalur kendaraan atau manusia

3. Prasarana PKL ditinggal ditempat lokasi jualan

4. Prasarana PKL kotor

Berkenaan dengan penilaian kumuh terhadap PKL, Kepala Bagian Perekonomian Pemda Șleman mengatakan bahwa:

Para PKL seharusnya tidak menempati tempat-tempat yang sebenarnya tidak boleh untuk berjualan dan kadang-kadang mereka membuang sampah/kotoran hanya di sekitar jalan atau tempat berjulan mereka. ${ }^{1}$

Berdasarkan peraturan dan penilaian pejabat Pemda Sleman bahwa keberadaan PKL dipinggir jalan atau trotoar adalah melanggar peraturan pemerintah. Namun aspek hukum tidaklah cukup untuk menyelesaikan masalah PKL. Oleh karena itu masalah pendekatan lokasi dan tempat usaha untuk memperoleh alternatif lokasi dan tempat usaha sesuai sifat PKL dan tata ruang perlu dilakukan secara konstrukstif mengkombinasikan keberadaan sektor formal dan informal secara terpadu.

Di jalan Kaliurang Km 4 dalam kompleks UGM terdapat dua jenis papan peraturan PKL yang berbeda. Salah satu peraturan dikeluarkan Pemda Sleman berbunyi:

"Dilarang berjualan dan meletakkan alat berjualan disini pada jam $6.30-16.30$," 
Sedangkan pihak UGM memberikan peraturan di trotoar Jl. Kaliurang yang berbunyi:

"Dilarang berjualan disepanjang jalan ini,"

Namun baik siang maupun malam, para PKL tetap berjualan di sepanjang trotoar jalan Kaliurang di kampus UGM. Dalam hal peraturan, sangat jelas bahwa para PKL tersebut melanggar, namun dalam kesempatan lain Pemda Sleman dan Satpam UGM menarik retribusi. Pengertian retribusi adalah pungutan uang oleh pemerintah (Badudu \& Zain, 2001). Pemerintah merupakan organisasi yang syah dalam mengatur suatu negara atau wilayah (Hornby, 1974). Sehingga bisa dinilai bahwa retribusi terhadap PKL mengesahkan usaha para PKL menempati lokasinya.

Dalam kenyataannya hingga sekarang para PKL di lokasi tersebut tetap berjualan pada siang dan malam hari. Bahkan para PKL yang buka malam hari, mereka memulai mempersiapkan usaha sejak jam 16.00. Sehingga bisa dikatakan bahwa peraturan yang tertulis tidak efektif. Jika mengacu pada peraturan Pemda Sleman bahwa PKL bisa berjualan pada malam hari di trotoar Ji. Kaliurang. Km 4 kompleks UGM maka para PKL diminta membayar retribusi sebesar Rp. 500 ,- per malam untuk Pemda Sleman, Rp. 125.000,- per bulan untuk keamanan polisi, dan Rp. 100.000,- per bulan untuk keamanan Satpam. Dari kondisi diatas dapat dikategorikan bahwa retribusi PKL terdiri dari:

\footnotetext{
- Sewa tempat

- Retribusi Pemda

- Retribusi Desa

- Retribusi Pemda dan Kampung

- Retribusi Pemda, Polisi dan Satpam

- Keamanan Kampung/Tokoh Masyarakat
}

Sejumlah masalah yang menarik dari aspek pemilihan lokasi PKL dan retribusi adalah:

1. Pengeloiaan lahan pinggir jalan atau trotoar yang tidak jelas sehingga ijin PKL dilakukan secara informal

2. Perijinan informal dan retribusi dilakukan berbagai lembaga dan perorangan dengan cara yang tidak seragam terjadi di berbagai lokasi PKL

3. Keragaman jenis retribusi (formal dan informal) menunjukkan kelemahan peraturan retribusi oleh Pemerintah daerah yang menimbulkan berbagai retribusi yang tidak resmi atau pemalakan yang menguntung hanya sebagian sedikit orang atau personil tertentu baik di pemerintahan maupun masyarakat.

Berbagai jenis bangunan sarana prasarana PKL di jalan Kaliurang dapat dilihat pada Tabel 5 dan 6. Untuk PKL pengolahan makanan pada umumnya berupa tenda dengan kerangka kayu, bambu atau besi. Sedangkan PKL perdagangan dan jasa pada umumnya menggunakan bangunan kios.

Jenis PKL pengolahan makanan menggunakan tenda dengan maksud mudah di bongkar dan dipasang kembali, karena bahwa $\mathrm{PKL}$ pengolahan makanan seperti di UGM, lokasi Seminari, dan Degolan pada umumnya berjualan pada malam hari (lihat Lampiran 1). Sedangkan PKL kios di jalan kaliurang pada umumnya berjualan pada siang hari dan mereka cenderung meninggalkan kios di lokasi mereka berjualan, Hal semacam ini yang menjadi keluahan masyarakat umum bahwa PKL posisinya mengganggu pejalan kaki (lihat Tabel 4) dan meberikan kesan kumuh ruang publik. 
Tabel 5: Jenis Bangunan PKL Pengolahan Makanan di sejumlah sampel di jalan kaliurang

\begin{tabular}{|c|c|c|c|c|}
\hline Lokasi Usaha & Jenis Makanan & Konstruksi Tenda & Bongkar Tenda & Luas (m2) \\
\hline $\begin{array}{l}\text { Jl. Kaliurang Km.7 } \\
\text { Jl. Kaliurang Km.7 } \\
\text { Jl. Kaliurang Km.7 }\end{array}$ & $\begin{array}{l}\text { - Lotek } \\
\text { - Bakmi, nasi } \\
\text { goreng, oseng2 } \\
\text { - Pecel lële, ayam } \\
\text { bakar . . }\end{array}$ & $\begin{array}{l}\text { - Tenda rangka kayu } \\
\text { dan bambu } \\
\text { - Tenda rangka bambü } \\
\text { - Tenda rangka kayū } \\
\text { dan bambu }\end{array}$ & $\begin{array}{l}\text { - Tidak dibongkar } \\
\text { - Tidak dibongkar } \\
\text { - Tidak dibongkar } \\
\text { - }\end{array}$ & $\begin{array}{l}3 \times 3=9 \\
3,5 \times 12=42 \\
3 \times 7=21\end{array}$ \\
\hline $\begin{array}{l}\text { J. Kaliurang } \mathrm{Km} 4 \\
\text { Jl. Kaliurang } \mathrm{Km} 4 \\
\text { Jl. Kaliurang } \mathrm{Km} 5\end{array}$ & $\begin{array}{l}\text { - Ayam goreng, nasi- } \\
\text { goreng } \\
\text { - Soto, rawon, taha } \\
\text { campur } \\
\text { - Soto } \\
\end{array}$ & $\begin{array}{l}\text { - Tenda rangka kayu dan } \\
\text { bambu } \\
\text { - Tenda rangka besi } \\
\text { - Tenda rangka besi }\end{array}$ & $\begin{array}{l}\text { - Tenda Dibongkar } \\
\text { - Tenda Dibongkar } \\
\text { - Tenda Dibongkar }\end{array}$ & $\begin{array}{l}2 \times 20=40 \\
2 \times 25=50 \\
3 \times 7=21\end{array}$ \\
\hline
\end{tabular}

Sumber: data primer

Lampiran 6: Jenis Usaha dan Bangunan PKL Kios Perdagangan dan Jasa

\begin{tabular}{|c|c|c|c|c|}
\hline Lokasi usaha & Jenis usaha & Bangunan & Sifat & Luas (m2) \\
\hline Jl. Kaliurang $\mathrm{Km} 13,5$ & Koran & Kios & Ditingal di lokasi & $2 \times 2$ \\
\hline Jl. Kaliurang $\mathrm{Km} 12$ & Stempel dan kunci & Kios & Ditingal di lokasi & $2 \times 1,5(2 b h)$ \\
\hline Jl. Kaliurang Km 11 & Plat nomor & Kios & Ditingal di lokasi & $1 \times 1,8$ \\
\hline Jl. Kaltuirang $\mathrm{Km} 5$ & Kunci & Kios & Ditingal di lokasi & $1,7 \times 2$ \\
\hline ग1. Kaluirang $\mathrm{Km}^{4} \mathrm{UGM}$ & Stempel & Kios & Ditingal di lokasi & $1,2 \times 2$ \\
\hline Jl. Kaluirang Km 4 UGM & Kelontong & Kios & Ditingal di Iokasi & $1 \times 2$ \\
\hline Jl. Kaluirang Komp UGM & Stempel, afdruk foto & Kios & Ditingal di lokasi & $0,8 \times 1,6$ \\
\hline Jl. Kaluirang Komp ÜGM & Plat nomor & Kios & Ditingal di lokasi & $1,5 \times 2$ \\
\hline
\end{tabular}

Sumber: Data Primer

Dari data diatas bisa ditemukan berbagai permasalahain PKL yang penting bagi penataan ruang yaitu:

1. Lokasi dan tempat usaha PKL yang sesuai dengan peraturan pemerintah

2. Lokasi dan tempat usaha yang sesuai dengan sifat $\mathrm{PKL}$ yang selalu ingin dekat dengan keramaian umum

3. Jenis bangunan yang sesuai dengan karakter PKL, seperti waktu berjualan, menetap, berpindah, bongkar pasang, dsb.

\section{Upaya Penataan PKL di Jalañ Kaliurang}

Keberadaan PKL merupakan sarana untuk membangkitkan ekoriomi kerakyatań, karena secara sosial politis, fungsi sektor usaha informal sangat diperlukan dalam hal penyerapan tenaga kerja yang dapat mendukung usaha pengentasan kemiskinan (Prananingtyas, 2001). Sektor informal perkotaan merupakan bagian dari masyarakat marginal dan jumlah mereka cenderung bertambah dari tahun ke tahun. Sehingga pendekatan penataan bagi PKL di perkotaan perlu difokuskan terhadap sektor informal dalam menuju pola penyusunan secara konstrukstif perkembangan sektor informal (Nesvåg, 2000) di perkotaan. Selain itu sektor informal mempunyai sifat bandel dan terbukti belum ada satu kotapun yang mempu menyingkirkan informal Oleh karena itu menjadi tranggung jawab pemerintah perkotaan dan masyarakat (urban stakeholders) untuk segera memikirkan dan menyatukan keberadaan sektor formal dan 
informal sebagai struktur masyarakat perkotaan (Suparwoko, 2005).

Pemerintah seyogyanya selalu mengusahakan dengan cara untuk mendekatkan sektor informal dengan sektor formal di perkotaan secara berdampingan untuk menjaga dan mendukung sektor formal modern. Sehingga sektor informal akan memperoleh arah perbaikan secara mandiri dalam melanjutkan usahanya untuk memperjuangkan hidupnya di perkotaan (Cross, 2000).

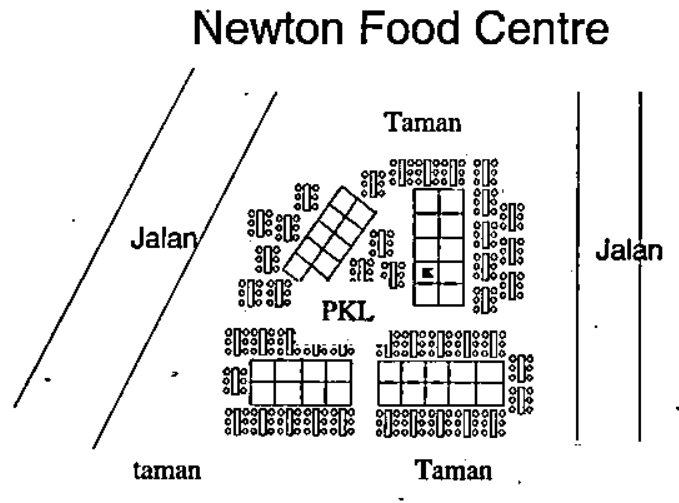

a. PKL Taman di Singapura
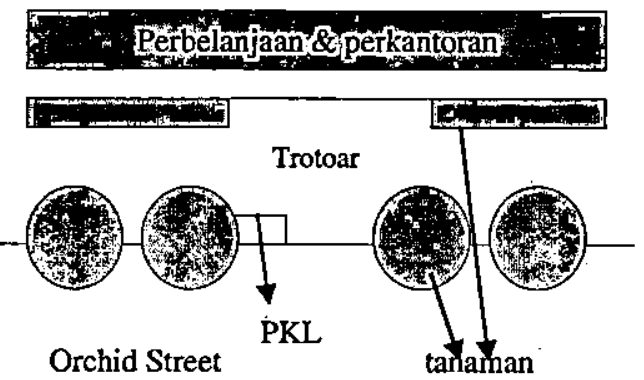

c. PKL di trotoar (8 m), Orchid Street, Singapura

\section{Clarck Quay}

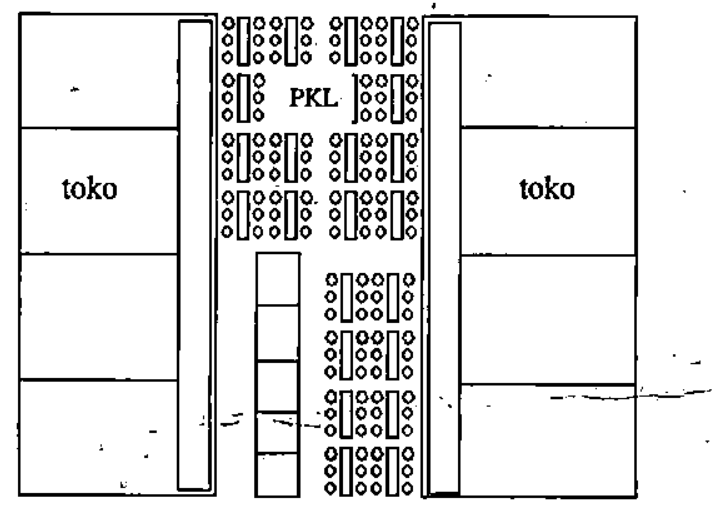

b. PKL diantara Pertokoan di Singapura

\section{Perbelanfaan \& perkantoran:}

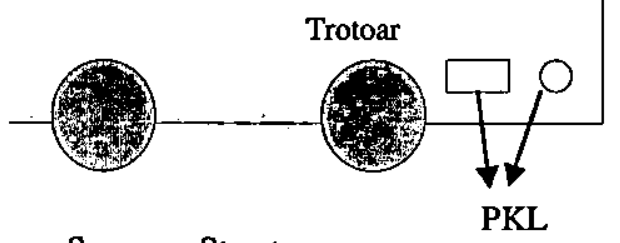

Swanson Street

d. PKL di trotoar $(8 \mathrm{~m})$, Swanson Street, Melbourne

\section{Gambar 2. Beberapa skema Penempatan PKL di Singapura dan Melbourne}

\section{Catatan Gamar 1:}

a. Kantong PKL berada di lingkungan jalan dan pertamanan kota

b. Kantong PKL pada area pedestrian diantara 2 pertokoan. PKL semacam ini bisa bongkar pasang.

c. PKL trotoar dengan jarak antar PKL disini adalah 50 meter. Sifat PKL movable Pola 2 PKL per blok dengan panjang trotoar 200 meter per blok, Sifat PKL permanen. 
Dikota besar besar dunia seperti Chcagi menunjukkan bahwa ekonomi informal di ruang publik perkotaan telah menambah semaraknya pelayanan perdagangan kepada masyarakat tinggal di wilayah kota. Sebagai konsekuensinya maka pemerintah daerah harus melakukan inspeksi dalam rangka penegakan hukum untuk menjaga keteraturan dan kebersihan serta kesehatan wilayah kota (Chicago's City Council, 2000).

Oleh karena itu penyusunaan konstruktif PKL di wilayah jalan Kaliurang perlu didasarkan atas tata kota, keterpaduan sektor formal-informal dan sifat kecocokan PKL di wilayah jalan Kaliurang karena sejumlah alasan, yaitu:

1. Peraturan daerah No. 11 tahun 2004 tentang Pedagang Kaki Lima bahwa PKL dapat melakukan kegiatan usahanya pada lokasi yang ditetapkan oleh Bupati (Pemerintah Kabupaten Sleman, 2004).

2. Surat Keputusan Bupati tahun 2004 tentang Usaha Informal. PKL bahwa klasifikasi bentuk bangunan tempat usaha informal adalah bentuk bangunan resto dan bangunan los.

3. Kecocokan penggunaan ruang publik bagi PKL (Cross, 2000)

Alasan ketiga merupakān pernyataan Cross (2000) yang mengatakan pemahaman para PKL tentang "kecocokan" penggunaan ruang publik di kawasan perkotaan berbeda dengan pihak pemerintah atau masyarakat lainnya. Para PKL berada dijalanan karena pihak perencana kota kurang memperhatikan keberadaan mereka yaitu tidak adanya tempat bagi para PKL untuk berjualan di ruang publik. Sedangkan diberbagai daerah atau negara dimana pemerintah daerah dan perencana kotanya memikir tempat bagi para PKL seperti pada Gambar 2.
Penentuan lokasi dan tempat usaha mengacu pada:

1. Perda PKL dan Pengelolaan usaha informal

Hingga sekarang Perda PK:L dan SK Bupati Sieman tentang pengelolaan usaha informal baru menentukan 3 lokasi PKL yaitu di Resto Mrican, PKL Los Manggung, dan PKL Condong Catur. Sehingga lokasi lain perlu diusulkan yang salah satunya melalui analisis lokasi pada penelitian ini.

2. Amatan lokasi dan tempat usaha PKL di negara tetangga

Berdasarkan hasil amatan karakter lokasi dan tempat usaha PKL di negara tetangga (Singapura dan Australia) terdiri dari beberapa jenis (lihat Gambar 2) yaitu:

- Kantong PKL berada di lingkungan fasilitas umum

- Kantong PKL pada area pedestrian, plasa, jalan yang bisa dibuka dan ditutup

- PKL trotoar dengan jarak tertentu dan bersifat movable atau bongkar pasang

3. Kriteria yang didasarkan atas sifat lokasi dan tempat usaha PKL di lokasi penelitian.

Berdasar data PKL yang diperoleh di lapangan bahwa:

- Pengguna atau konsumen terbanyak para PKL adalah mahasiswa

- Jumlah mahasiswa terbanyak berada di Kabupaten Sleman, terutama Jalan Kaliurang

- PKLyang dibutuhkan terbanyak adalah pengolahan makanan

- PKL lebih banyak beroperasi pada malam hari, terutama PKL jenis pengolahan makanan untuk pelyanan mahasiswa.

PKL menyukai daerah ramai termasuk adanya perguruan tinggi, fasilitas umum (termasuk lokasi dekat perumahan- 
pondokan dan fasilitas perdagangan). Banyak pondokan yang berada di perumahan atau permukiman di kawasan sekitar kampus atau perguruan tinggi. Sehingga kriteria lokasi PKL berdasar sifatnya adalah:

1. Lokasi di pinggir jalan

2. Lokasi dekat keramaian kampus

3. Lokasi dekat keramaian perumahan/ pondokan

4. Lokasi dekat keramaian perdagangan dan jasa

Berdasarkan pertimbangan diatas maka upaya penataan lokasi dan tempat usaha PKL di jalan Kaliurang dapat dilihat pada Tabel 5. Dalam proses penyediaan lokasi bagi PKL (baik PKL yang bersifat metetap maupun berpindah) adalah untuk I menangani jumlah PKL eksisting yang ada sekarang. Untuk mendukung usaha ini PKL eksisting perlu membuat organisasi untuk mengolah jumlah PKL dan ketersediaan lahan disekitar jalan Kaliurang. Berbagai lokasi dan lahan yang dapat digunakan untuk PKL disekitar jalan raya adalah lahan dekat lapangan (Gentan), halaman atau tempat parkir usaha perdagangan dan jasa di sekitar jalan Kaliurang yang kegiatan usaha atau pelayanannya tutup pada sore atau malam hari, seperti toko besi, bengkel, perkantoran (pemerintah/swasta), tempat cucian mobil, dsb.

Untuk PKL baru dimasa mendatang perlu diarahkan penempatannya pada fasilitas umum baru yang potensial untuk memberikan keramaian seperti perumahan, fasilitas perdagangan dan jasa. Setiap pembangunan perumahan, fasilitas umum (perdagangan dan jasa) yang baru perlu menyediaaan lokasi bagi PKL untuk mereka agar dapat berjualan. Lokasi dan tempat usaha PKL pada fasum dan fasos tidak diberikan atau dijual, melainkan digunakan dengan cara disewà. Hal ini dilakukan untuk menampung jumlah PKL yang setiap tahunnya terus bertambah. Masyarakat PKL di Sleman telah membentuk organisasi yang menampung paguyuban-paguyuban $P K L$ di berbagai lokasi. Namun hingga sekarang belum semua masyarakat PKL mempunyai paguyuban. Sehingga para PKL yang sekarang ada sebaiknya membentuk paguyuban dan bergabung dengan PPKLS. Sehingga para PKL yang baru akan diarahkan pada lokasi fasilitas umum yang berada di halaman atau dekat dengan tempat parkir fasilitas umum tersebut. Sebagai contoh:

1. Lokasi perumahan dengan jumlah $>50$ unit diwajibkan memberikan fasum dan fasos, maka PKL akan berada pada area fasum/fasos tersebut dengan cara sewa.

2. Fasilitas umum perdagangan dan jasa, selain wajib menyediakan ruang parkir, maka sebagaian ruang parkir tersebut bisa disewakan bagi PKL.

\section{Penutup}

Sektor informal perkotaan seperti PKL telah menjadi bagian penting dari sistem perekonomian perkotaan secara menyeluruh, sehingga keberadaan PKL tidak bisa dipisahkan dengan keberadaan sektor formal perkotaan. PKL di jalan Kaliurang tumbuh karena adanya kampus/perguruan tinggi, perumahan, pemondokan dan fasilitas umum berupa perdagangan dan jasa. Sehingga kehadiran PKL diperkotaan merupakan tanggung jawab bersama antara pemerintah, dan masyarakat terutama mereka pengelola perguruan tinggi, perumahan, dan fasilititas perdagangan dan jasa. Dalam kenyataannya keberadaan sebagian PKL di jalan Kaliurang berada di tempat usaha dan lokasi yang menyebabkan gangguan bagi pejalan kaki dan kendaraan. Selain itu sebagian bangunan PKL yang 
Tabel 6. Analisis Lokasi dan Tempat Usaha PKL di kawasan Tumbuh Cepat Kabupaten Sleman

\begin{tabular}{|c|c|c|c|c|c|c|c|c|c|c|c|}
\hline \multirow[t]{2}{*}{$\begin{array}{l}\text { Lokasi } \\
\text { eksisting }\end{array}$} & \multicolumn{3}{|c|}{$\begin{array}{l}\text { Jenis PKL } \\
\text { eksisting }\end{array}$} & \multicolumn{3}{|c|}{ Usulan Lokas' } & \multicolumn{4}{|c|}{$\begin{array}{l}\text { Kriteria Lokasi } \\
\text { yang dipenuhi }\end{array}$} & \multirow[t]{2}{*}{ Alternatif lokasi, tempat usaha, dan bangunan PKL } \\
\hline & 1 & 2 & 3 & 1 & 2 & 3 & 1 & 2 & 3 & 4 & \\
\hline $\begin{array}{l}\text { Jl. Kaliurang - } \\
\text { UGM } \\
\text { Jl. Kaliurang } \\
\text { merupakan jalan } \\
\text { kolektor primer }\end{array}$ & $\mathbf{v}$ & $\mathrm{v}$ & & $\mathrm{v}$ & & & $\mathrm{v}$ & $\mathbf{v}$ & $\mathrm{v}$ & & $\begin{array}{l}\text { - PKL trotoar } 1 \text { sisi (barat) Jl. Kaliurang UGM dan PKL } \\
\text { pinggir jalan pada jalan sebelah utara Pusat Bahasa dan } \\
\text { FKG - UGM } \\
\text { - Bangunan tenda bongkar pasang untuk PKL pengolahan } \\
\text { makanan } \\
\text { - Kios movable untuk PKL perdagangan dan jasa, termasuk } \\
\text { PKL buah } \\
\text { - Masalah parkir dapat dikurangi dari } 2 \text { sisi menjadi satu sisi }\end{array}$ \\
\hline $\begin{array}{l}\text { Jl. Kaliurang } \\
\text { Degolan } \\
\text { Jl. Kaliuran } \\
\text { merupakan jala } \\
\text { kolektor primer }\end{array}$ & & $\mathbf{v}$ & $\mathbf{v}$ & & $\mathbf{v}^{-}$ & & $v$ & $v$ & $\mathbf{v}$ & & $\begin{array}{l}\text { - Kantong PKL di kampus UII, dengan bangunan semi } \\
\text { permanen dan Kantong Parkir Akademi Perawat bestersda } \\
\text { dengan bangunan tenda } \\
\text { - PKL halaman fasilitas perdagangan dan jasa sekitar } \\
\text { kampus UII } \\
\text { - Mengurangi masalah parkir pinggir jalan }\end{array}$ \\
\hline $\begin{array}{l}\text { Jl. Kaliurang } \\
\text { PLN } \\
\text { Jl. Kaliuran } \\
\text { merupakan jala } \\
\text { kolektor primer }\end{array}$ & & $\mathbf{v}$ & & $\mathrm{v}$ & & & & $\mathbf{v}$ & $v$ & & $\begin{array}{l}\text { - PKL pinggir jalan sisi timur, sisi barat dikosongkan } \\
\text { - PKL pengolahan makanan malam hari dan PKL } \\
\text { perdagangan dan jasa pada siang hari } \\
\text { - Pada sis timur jalan masih ada ruang parkir di bahu jalan } \\
\text { selebar } 3 \mathrm{~m}\end{array}$ \\
\hline $\begin{array}{l}\text { Jl. Kaliurang } \\
\text { Seminari } \\
\text { (Jl } \\
\text { primer) }\end{array}$ & & $v$ & & $\mathbf{v}$ & & & & $\mathbf{v}$ & $\mathbf{v}$ & & $\begin{array}{l}\text { - PKL pinggir jalan di satu sisi barat, dan sisi timur } \\
\text { dikosongkan } \\
\text { - Masalah parpir bisa dikurangi }\end{array}$ \\
\hline
\end{tabular}

\section{Catatan:}

- Jenis tempat: 1. PKL trotoar, 2. PKL pinggir Jalan, 2. PKL halaman

- Usulan Lokasi: 1. Tetap, 2. Pindah, 3. Tetap dan pindah Kriteria Lokasi: 1. Dekat kampus, 2. Dekat fasilitas perdagangan dan jasa, 3. Dekat dengan perumahan/permukiman/pondokan,
4. Dekat dengan perkantoran 
bersifat non permanen dan kotor ditinggal di tempat mereka melakukan usaha, sehingga menyebabkan kondisi jalan Kaliurang menjadi nampak kumuh di lokảsi para PKL berjualan. Oleh karena itu upaya penataan perlu dilakukan untuk mengurangi masalah tersebut.

Upaya penataan PKL di jalan Kaliurang bersumber pada lokasi dan tempat usaha yang sesuai dengan peraturan pemerintah dan pendekatan karakter PKL pada aspek lokasi, tempat usaha, dan bentuk bangunannya. Lokasi yang cocok bagi PKL di jalan Kaliurang adalah dekat kampus UGM, UII, Akper Betesda, dan dekat dengan fasilitas perdagangan dan jasa. Berdasarkan kondisi tersebut maka:

1. PKL di jalan Kaliurang UGM perlu diarahkan hanya menempati satu sisi dari jalan tersebut.

2. PKL di sekitar kampus UIl dan Akper perlu melakukan pendekatan dengan kampus tersebut dengan dukungan Pemda Sleman dan PPKLS

3. Lokasi PKL diarahkan pula menempati sebagian lahan lapangan Gentan (pinggir jalan) dengan cara menyewa. Upaya ini perlu dukungan Pemda Sleman, Pemerintah Kecamatan, Desa setempat dan PPKLS. Alternatif tian lahan milik Desa perlu disediakan dengan cara mencari bersama-sama antara mayarakat PKL dan pihak pemerintah.

4. Para PKL di Jalan Kaliurang periu membentuk organisasi untuk memudahkan proses penataan dan proses pengambilan keputusan serta negosiasi. Para PKL yang belum bisa menempati lokasi yang telah disebutkan diatas maka para PKL tersebut perlu menempati lahan parkir, halaman berbagai fasilitas perdagangan dan jasa (termasuk perkantoran) yang tidak melakukan aktifitas pada malam hari.

5. Untuk jangka panjang, para PKL disepanjang jalan Kaliurang yang tumbuh dari tahun ke tahun perlu bergabung dengan organisasi PKL melalui proses pendafțaran. Secara kelembagaan organisasi PKL akan para PKL yang tumbuh di masa mendatang. Pendaftaran PKL-baru perlu dilakukan untuk keperluan penempatan mereka selanjutnya.

6. Untuk mengalokasikan PKL baru yang telah terdaftar pada organisasi PKL jalan Kaliurang maka mereka akan diarahkan untuk menempati lahan fasum dan fasos yang tumbuh di sekitar jalan kaliurang seperti perumahan, pedagangan dan jasa. Penempatan PKL pada sebagian lahan fasilitas umum tersebut dilakukan dengan cara sewa.

7. Untuk mewujudkan alternatif penataan PKL di jalan Kaliurang tersebut maka hubungan dan kerja sama antara PPKLS, komunitas PKL jalan Kaliurang. Pemerintah Daerah Sleman (termasuk tingat kecamatan dan desa), Perguruan Tinggi serta masyarakat lokasi setempat perlu dilakukan secara berkelanjutan.

\section{Daftara Pustaka}

Alimi, T. (2004). Migrasi Urbanisasi dalam Era Perdagangan Global. Retrieved 1 Juni, 2004, from http:// www.lead.or.id/tulisan.php?id=1610

Badudu, J. S., \& Zain, S. M. (2001). Kamus Umum Bahasa Indonesia. Jakarta: Pustaka Sinar Harapan.

Bagian Pengembangan Perekonomian Sekretariat Daerah Kabupaten 
Upaya penataan PKL diperkotaan: Studi kasus Jalan Kaliurang; Suparwoko

Sleman. (2003). Laporan Kegiatan Up-dating Data Usaha Pedagang Kaki Lima Di Kecamatan Depok, Mlati, Ngaglik, Sleman, dan Gamping, Kabupaten Sleman. Sleman: Pemerintah Kabupaten Sleman.

BPS Kabupaten Sieman. (2003a). Kecamatan Depok Dalam Angka 2003. Sleman: BPS dan Bappeda Kabupaten Sleman.

BPS Kabupaten Sleman. (2003b). Kecamatan Gamping Dalam Angka 2003. Sleman: BPS Kabupaten Sleman.

BPS Kabupaten Sleman. (2003c). Kecamatan Mlati Dalam Angka 2003. Sleman: BPS Kabupaten Sleman.

BPS Kabupaten Sleman. (2003d). Kecamatan Ngaglik Dalam Angka 2003. Sleman: BPS Kabupaten Sleman.

Chicago's City Council in Alfonso Morales. (2000). Peddling Policy: Street Vending in Historical and Contemporary Context. Intemational Joumal of Sociology and Social Policy, 21(3/4).

Cross, J. C. (2000). Street Vendors, Modernity and Postmodemity: Conflict and Compromise in the Global Economy. Intemational Joumal of Sociology and Social Policy, 21(1/2).

Deputi Sekretaris Kabinet Bidang Hukum Perundang-undangan. (2004). Undang-undang Republik Indonesia No. 38 Tahun 2004 tentang Jalan. Jakarta: Deputi Sekretaris Kabinet
Bidang Hukum dan Perundangundangan.

Dinas Perhubungan DIY. (2004). Penyusunan Tataran Transportasi Wilayah Propinsi Daerah Istimewa Yogyakarta. Yogyakarta: Pusat Studi Transportasi dan Logistik - UGM.

Hornby, A. (1974). Oxford Advanced Learner's Dictonary of Current English. Oxford, Great Britain: Oxford University Press.

McGee, T. G., \& Yeung..(1977): Hawkers in South East Asiañ Cities: Planning for the Bazaar Ekonomy. Ottawa: International Development Centre.

Natalivan, P., \& Dwiananto, S. (2005). Intemalisasi sektor informal dalam rencana tata ruang kota. Paper presented at the Seminar Nasional: Pembangunan Lingkungan Perkotaan di indonesia: Masalah, Tantangan dan Peluang Dalam Menghadapi Era Globalisasi, Jakarta.

Nesvåg, S. I. (2000). Street trading from Apartheid to Post-Apartheid: More birds in the comfield? International Journal of Sociology and Social Policy, 21(3/4).

Pemerintah Kabupaten Sleman. (2003). Rencana Tata Ruang dan Wilayah Kabupaten Sleman tahun 2003. Sleman:Pemerintah Daerah Kabupaten Sleman.

Pemerintah Kabupaten Sleman. (2004). Peraturan Daerah Kabupaten Sleman. Sleman: Pemerintah Kabupaten Sleman. 
Topik: Keterpaduan Sektor Formal dan Informal Perkotaan

PPKLS. (2005). Usulan Penataan PKL di Sejumlah Lokasi Kabupaten Sleman. Sleman: PPKLS.

Prabowo, K. (2005, Maret). Solusi Penataan PKL Sleman. Corong, pp. 2-3.

Prananingtyas, P. (2001). Pembaharuan Peraturan Perundang-undangan - MengenaiUsaha Kecil dan Menengah di Indonesia. Unpublished manuscript, Semarang.

Beddy, M., Naidu, V., \& Mohanty, M. (2002). impediments and Growth Dynamics of Urban Informal Sector. Â. Case Study of Fiji's Urban Informal Sector. Retrieved 7 Agustus, 2004, from http://www.devnet.org.nz/conf2002/ papers/Reddy-Naidu Mohanty.pdf
Streetnet. (2005). Focus on Street Vendors Asia. Retrieved November 20, 2005, from http://www.streetnet.org.za/ asiafeature.htm

Suparwoko. (2005). Pola Hubungan Sektor Formal Informal di Perkotaan: studi kasus penataan PKL di Sleman, DI Yogyakarta. Paper-presented at the Pembangunan Lingkungan Perkotaan di Indonesia, FALTL - Universitas Trisakti, Kampus A Gedung K, Lantai 7, Jl. Kyai Tapa No 1, Grogol Jakarta 11440.

Witjaksono, A. (2005). Bagaimana kegiatan __. In útmal (Pedagang Kaki Lima) Dapat Mendukung Perkembañgan Kóta?? In F.-U. T. Panitia Seminar (Ed.), Pembangunan Lingkungan Kota di Indonesia. Jakarta: FALTL - Universitas Trisakti. 